\title{
Н.А. Касавина
}

\section{О ЦЕННОСТИ НАУКИ (ОТВЕТ А.Л. НИКИФОРОВУ) ${ }^{1}$}

\begin{abstract}
Нововременная направленность науки на «чистую» истину рассматривается как реакиия на чрезмерный морализаторский и соииальный детерминизм эпохи, стремление отдельных областей культуры обрести свои специфические функиии и развиваться вне тотального влияния церкви или государства. Наука Нового времени анализируется как поиск истины, как источник технонауки, как фактор духовного развития человека и общества.

Ключевые слова: наука Нового времени, ценность науки, технонаука.
\end{abstract}

Вопрос о цели науки и ответ на него в пользу поиска «чистой» наукой истины при условии ее «беспристрастности, неангажированности и свободы от ценностных установок» напоминает о сходной тенденции в искусстве. Имеется в виду эстетизм - европейское движение в искусстве конца 1860-х1890-х гг., которое подчёркивало преобладание эстетических ценностей над этическими и над социальными проблемами. «Наука ради истины» и «искусство ради искусства»: каковы истоки этих не единственных тенденций, ставящих цели специализированной деятельности выше универсальных потребностей общества?

Романо Гвардини называет нововременное стремление к познанию «охотничьей страстью испытания», которая преследует природную или историческую действительность, чтобы, догнав, «эмпирически пригвоздить ее и, одолев, теоретически подчинить...». Стремление же к познанию, осуществлявшееся до Нового времени, «медитируя, погружается в истину, чтобы вынести из нее духовную конструкцию бытия» [1]. Исследовательская установка как таковая развивается в Новое время. Для культуры и сознания Средних веков она выступает как чуждая, внушающая страх и нарушающая равновесие бытия.

Нововременную направленность науки на «чистую» истину можно рассматривать как реакцию на чрезмерный морализаторский и социальный детерминизм эпохи [2], стремление отдельных областей культуры обрести свои специфические функции и развиваться свободно, без тотального влияния церкви или государства. Наука стремится к автономии, которую ей пришлось не одно столетие отвоёвывать в революционной борьбе с авторитарным образом мышления. В истории масса примеров несвободы науки, трагичности научного поиска, находящегося во власти господствующих структур. Это было актуально и для Нового времени - эпохи, последовавшей за догматизмом Средних веков.

Действительно ли наука Нового времени была чистым поиском истины, вдохновляемым только познавательным интересом, или она возникала как технонаука, отвечая потребностям организации жизни общества?

\footnotetext{
${ }^{1}$ Статья подготовлена при поддержке Российского научного фонда, проект №14-18-02227, «Социальная философия науки: российская перспектива».
} 
На этот вопрос нельзя ответить однозначно. По словам А.Л. Никифорова, «наука является способом создания и совершенствования техники на базе достоверных (истинных) знаний». Из приведенных А.Л. Никифоровым рассуждений следует, что и эта база истинных знаний также обязана стремлению человека и общества к созданию и развитию техники.

Видимо, здесь необходимо говорить о разных путях технического и научного развития. С одной стороны, имеет место эволюционное развитие техники; сфера хозяйства, обеспечения практических нужд общества выступает основанием получения новых знаний. Именно в практике человечество постигало законы природы и совершало важнейшие технические открытия. С другой стороны, история техники включает в себя скачки, обязанные в большей степени научному развитию, получению новых знаний, чем предшествующей практике, что особенно проявилось в эпоху Возрождения и Нового времени.

Развитие машинной техники традиционно связывается с развитием естествознания. Формирование же самого естествознания и основанной на его успехах инженерной деятельности нередко рассматривается как следствие актуализации потребностей развивающейся промышленности. В этом сложность союза науки и техники, когда каждое из составляющих может быть основанием развития другого и их синтез определяет развитие общества.

Кроме того, создание некой техники предполагает осознание возможности и необходимости технического решения тех или иных потребностей. Сознание, в том числе научное, претерпевает определенные изменения, и эти изменения осуществляются не только под влиянием техники.

В понимании А.Л. Никифорова, наука призвана служить решению технологических задач, которые ставит перед ней общество. Связка «наука технология - общество» отнюдь не так однозначна. Чтобы общество могло ставить эти задачи, оно должно развиваться, и развиваться под влиянием как науки, так и техники. В этом синтезе практически невозможно, да и вряд ли нужно, отличать первичное от вторичного. В этой связи, как удачно отмечает А.Л. Никифоров, развитие науки, в том числе и как технонауки, определяется ее включенностью в культуру.

Следующий вопрос касается того, что же дала технонаука Нового времени человечеству? Дала ли что-то наука для духовно-нравственного развития человека, пыталась ли она ответить на самые важные вопросы человеческого существования? Об этом интересно поразмышлять, и эта проблема, безусловно, важна для современного самоопределения науки.

Нововременное стремление к познанию связано со стремлением ученого обратиться к непосредственной действительности вещей. Он, как пишет Р. Гвардини, «хочет - независимо от заданных образцов и авторитета - увидеть все своими глазами, испытать собственным рассудком и получить критически обоснованное суждение» [1]. Он обращается к природе через эксперимент и рационализм Нового времени; к человеку - через складывающиеся тенденции гуманизма; к общественной жизни - через поиск новых учений о государстве и праве. Наука, ищущая автономности в культуре, стремится к освобождению от догматизма и утверждению самостоятельности. Нововременная наука в некотором смысле действительно не наполняет знание духов- 
ным содержанием, а стремится от него избавиться, не отделяя духовное от религиозного.

Если трактовать науку Нового времени как технонауку, можно предположить, что она действительно не стремилась дать свои ответы на эти «важные», скажем, экзистенциальные вопросы. Ее задачи лежат в иной плоскости. Технонаука разрабатывает конкретные элементы жизнеустройства. Вместе с тем их разработка была бы невозможна, если бы технонаука не опиралась на некий экзистенциальный горизонт в понимании человека и культуры. Культурный контекст, созданный этим горизонтом, служит основанием того, что технонаука занимается развитием жизни человека и общества [3]. Чтобы вооружить человека средствами его преобразования, нужно поверить в него как ценность.

Отношение к духовному в Новое время существенно меняется. Мир расширяется, становится бесконечным, его границы размываются, и исключительное значение данного мира становится сомнительным. Набирает темпы процесс секуляризации культуры, создается картина мира, ориентированная на эту, посюстороннюю, действительность, которую необходимо обустраивать (в том числе с помощью технонауки). «Возникает уходящая во все стороны бесконечная связь: с одной стороны, она дает простор и свободу, с другой - лишает человеческое существование объективной точки опоры. Человек получает простор для движения, но зато становится бездомным» [1]. Складывается характерное для Нового времени сознание личности, которая превращается в предмет наблюдения и психологического анализа складывающейся сферы гуманитарного знания.

Если рассматривать нововременную науку как систему, содержащую основания нового взгляда на человека и поворота к развитию социальногуманитарных наук, то становится очевидным, что исследование духовнопрактических вопросов является ее существенной частью. Причем эти основания проявили себя как результат гуманистической и во многом романтической настроенности культуры, с одной стороны, и переживанием «бездомности» человека секулярной культуры - с другой.

Отвечая на вопрос, дала ли наука личности только знания о мире и технические средства или же внесла вклад также и в духовное развитие, необходимо принимать во внимание сложность и неоднозначность соотношения витального, интеллектуального, духовного и других составляющих человека. Под влиянием мировоззрения Средних веков тело и телесные, биологические потребности относились к сфере низменного в человеке и культуре. Со временем эти представления изменились, и телесность сегодня в различных концепциях представляется как неотъемлемая часть духовного развития, как одно из его оснований и конкретных воплощений. Человеческая телесность включена в духовное становление, она является результатом онтогенетического, личностного развития, выражает культурную и смысловую его составляющие.

В этой связи наука, способствуя совершенствованию сферы знания, технологий, играет важную роль и в духовном развитии человека и общества. Духовное развитие при этом не предстает в контексте картезианского дистанцирования от «низменной» биологической природы. Технические средства покорения и преобразования природы, о которых сказано в статье 
А.Л. Никифорова, независимость человека от расстояний и различных природных ограничений многое сделали с его духовным миром, с человеческим в человеке. Иное дело, что все «трансцендентные пункты» (по выражению того же Р. Гвардини) были определены другими эпохами, предшествовавшими временам технонауки, и вряд ли можно представить, что эпохи, последовавшие за Античностью и Средними веками, могут добавить к этим пунктам что-то существенное.

В завершение хотелось бы отметить, что идеи, выдвинутые А.Л. Никифоровым, безусловно, важны и интересны для осмысления истории науки в контексте культуры, современного развития науки, ее предназначения и роли в жизни человека и общества, соотношения науки и техники. Помимо этого, статья содержит явный упрёк автора по отношению к науке, разочарование в ее способности существенно продвинуть человека, культуру, общество в направлении их духовного роста. Это разочарование испытывают сегодня многие, осознавая всю мощь современных технических достижений и робкое движение (вперед или назад, еще неизвестно) человечества в его духовном прозрении. Да, хотелось бы, чтобы наука не просто совершенствовала технику, но и существенно помогла человеку в решении его человеческой, духовной, экзистенциальной ситуации, что-то сделала для облегчения экзистенциального бремени, созданного секулярной культурой, внесла вклад в гармонизацию человека как носителя особой телесности, сознания, культуры.

Однако стоит обратить внимание на то, что наука Нового времени определена культурным контекстом, ее характер сложился как ответ на вызов предшествующих эпох и она включает в себя поиск истины, которая ценна не только своими техническими следствиями. Нововременная наука «запустила» тот облик ученого, который и сегодня работает, исследует, вступает в коммуникацию [4]. В определении науки как «способа создания и совершенствования техники на базе достоверных (истинных) знаний» я бы поставила второе на место первого, обозначив тем самым вектор понимания не только технологической ее ценности в обществе, но и мировоззренческой, духовной. Трактуя науку как технонауку, не стоит забывать о широком спектре социально-гуманитарных исследований и технологий [5], которые работают с человеком как носителем «специфически человеческого» и обязаны тому взгляду на личность, который укрепился в Новое время.

\section{Лumepamypa}

1. Гвардини Р. Конец Нового времени // Вопросы философии. 1990. № 4. С. 127-164.

2. Whewell $W$. Philosophy of the Inductive Sciences, Founded upon their History // Epistemology \& Philosophy of Science. 2016. Vol. 49. Iss. 3. P. 198-215.

3. Stoliarova O.E. Technoscience as an Experimental Environment and Experimental Methodology // Epistemology \& Philosophy of Science. 2016. Vol. 48. Iss. 2. P. 40-44.

4. Kasavin I.T. History of Science a la Belle Lettre: a Case of Laura Snyder // Epistemology \& Philosophy of Science. 2016. Vol. 48. Iss. 2. P. 233-237. P. $3-30$.

5. Lektorskiy V.A. et al. Humanities and Social Technologies // Voprosy filosofii. 2013. Iss.7.

Nadezhda A. Kasavina, Institute of Philosophy, Russian Academy of Sciences (Moscow, Russian Federation).

E-mail: kasavina.na@yandex.ru 
Vestnik Tomskogo gosudarstvennogo universiteta. Filosofiya. Sotsiologiya. Politologiya - Tomsk State University Journal of Philosophy, Sociology and Political Science. 2018. 42. pp. 213-217.

DOI: $10.17223 / 1998863 \mathrm{X} / 42 / 25$

ON THE VALUE OF SCIENCE (A REPLY TO ALEXANDER NIKIFOROV)

Keywords: modern science; value of science.

The course of modern science to pure truth is a reaction to the excessive moralizing and social determinism of the era. It is the desire of certain cultural industries to regain their specific functions and develop freely, without the total influence of the Church or the State. Science sought autonomy, which it had for centuries fought for in the struggle with the authoritarian mindset. If one interprets modern science as technoscience, it assumes that it has not sought to give its answers to existential questions. Its tasks lie in a different plane. Technoscience develops specific elements of life. However, their development would not have been possible if technoscience had not relied on the existential horizon in understanding man and culture. The existential-cultural context justifies the fact that technoscience is engaged in the development of human life and society. To provide means of human transformation, it is necessary to believe in it as a value. Modern natural science is a platform for the development of social and human sciences and plays an important role in the spiritual development of man and society. This development is the result of the humanistic and romantic mood of culture, on the one hand, and the experience of "homelessness" of secular culture, on the other. Spiritual development does not appear as distancing from the "ignoble" biological nature. Influenced by the ideology of the Middle Ages, the body and physical, biological needs were related to the sphere of shame in man and culture. Over time, these views have changed and physicality today is presented in different concepts as an integral part of spiritual development, as one of its bases and specific incarnations. Human physicality is included in spiritual formation, it is the result of ontogenetic, personal development manifesting its meaning and cultural components. Modern science has created the image of a scientist who works, explores and enters into communication nowadays. While treating science as technoscience, it is necessary to take into account a wide range of social-humanitarian research which studies humans as bearers of "human specificity" due to the modern view on personality.

\section{References}

1. Guardini, R. (1990) Konets Novogo vremeni [The End of New Time]. Voprosy filosofii. 4. pp. $127-164$.

2. Whewell, W. (2016) Philosophy of the Inductive Sciences, Founded upon their History. Epistemologiya i filosofiya nauki - Epistemology \& Philosophy of Science. 49(3). pp. 198-215.

3. Stoliarova, O.E. (2016) Technoscience as an Experimental Environment and Experimental Methodology. Epistemologiya i filosofiya nauki - Epistemology \& Philosophy of Science. 48(2). pp. 40-44. (In Russian).

4. Kasavin, I.T. (2016) History of Science a la Belle Lettre: a Case of Laura Snyder. Epistemologiya i filosofiya nauki-Epistemology \& Philosophy of Science. 48(2). pp. 233-237. (In Russian).

5. Lektorskiy, V.A. et al. (2013) Humanities ans Social Technologies. Voprosy filosofii. 7. pp. 330. (In Russian). 